\title{
In Conversation with Peter Sainsbury
}

Hugh Freeman interviewed Dr Sainsbury on 6 November 1987 at his home in Sussex.

HF As psychiatrists we are supposed to be interested in people's early life and background, so I wonder if you would tell me something about yours and if you think it had any relationship to your later career?

PS I was born to a middleclass family in 1916. My mother and father were bright young things in the 1920s and part of that set. I was sent as a boarder to a prep school just up the road in the street where I lived, when I was five years-old. I think that might have had some influence on my future development!

But I suppose things started becoming interesting in relation to my career when I was at Stowe school. At Stowe, I was placed in the bottom form and got stuck there. Nevertheless, I was very interested in science and used to read a good deal. In fact, I knew a lot of biochemistry at that age and also read a bit of psychology and physics; but at the bottom of the school, one did not study the sciences. The headmaster, Roxburgh, was one of England's great headmasters: an admirable figure whom we all tried to emulate, particularly his language. $\mathrm{He}$ would complain "what a lamentable performance, Sainsbury"; or "egregious student"! We delighted in his love of words, and this remained with me. He worried about me being stuck there and started quizzing me about why this was; then, I was able to tell him that the only thing that really interested me and that I felt I was any good at was science. So he broke the rules and let me study chemistry and physics. From then onwards, my academic career took off and the interesting thing is how one's performance at other subjects improves as well, as soon as one gets going. I was told I got the highest marks in England in my school certificate in chemistry, $99 \%$ ! Next, my interests turned to biology, and so I started on the path to studying medicine.

HF I would like to ask you two things next. Firstly, what was your home atmosphere like-you say your parents were bright young things. And secondly, what was your experience of boarding schools?
PS Home was really quite exciting, my parents were always going to cocktail parties, treasure hunts in motor cars and such like. My brother, sister, and I were left to the care of our nurse, whom I adored and visited often until she died last year. But they attracted a lot of interesting people, who had quite an effect on me, into the home. My father started an amateur theatrical company, the Horsham Players, which became quite well known, and people like Miles Malleson used to produce the shows; but these theatricals instilled an enduring fear in me of public performances. And when I was a bit older, I became very attached to Allen Lane, and helped to choose books for the first series of Penguins.

I did not like boarding school but Stowe was about the best option one could have at the time. It was a fairly progressive school and the buildings and grounds were very beautiful-the headmaster taught us to share his love of 18 th century architecture. So Stowe not only helped me to become a scientist but also excited an enduring pleasure in buildings, gardens, and music too.

HF I would like to ask you now about the point when you left school and how you then started on your course towards medicine.

PS I left school when I was taking my higher certificate. I left it early as I did not really enjoy being a boarder, so I went up to Bart's for a year prior to going to Cambridge. I did very little studying at Bart's; it was really a year off in London, the sort of thing young people do nowadays between school and university. Then I went to Trinity when I was 17 . Cambridge was a fascinating place in 1935. I am amused by all the fuss these days about the left-wing traitors in Cambridge, but it was part and parcel of the ethos of the young men and women there. We sought a brave new world; a lot of my friends joined the Communist Party, and some of them went to Spain. A friend of mine, John Cornford, who was at Stowe with me, was killed there on his 21st birthday. That was how people thought in the 1930s. You either hated and demonstrated against Mussolini, Hitler and Chamberlain, joined the Left Book Club, and were part of that set, or missed out on the great issues of that age. We undergraduates were among the first to take up the cudgels against Nazism, and were re-labelled patriots as the war approached.

At Cambridge, I enjoyed the opportunity to get down to studying physiology and biochemistry. The biochemistry department was very exciting, inhabited by people like Needham, Bernal and Hopkins. It 
was at the this time that I first developed an interest which was going to be important to me for the rest of my working life. I was fascinated by Cannon and the physiology of fear and emotion and had a fantasy that this was what I was going to study. In fact, some of my first research at the Maudsley was in the psychophysiological area; but it was unrealistic in 1935 to think that I might have opportunities to study disorders of that kind.

HF Are there any of your fellow undergraduates that you particularly remember from that time?

PS Yes. The ones who are most relevant to what we are talking about now were the radical young scientists, one of whom had been Head Boy at Eton and became a communist. Four of this group became directors of MRC Units.

HF Who were the other three?

PS Waterlow, Humphreys and Gell.

HF Let's talk now about the point when you left Cambridge and went on to hospital work.

PS After Cambridge, I went to the Middlesex Hospital where my father had been a dental student. But teaching was disrupted by the war, and after a year there, we were evacuated to Aylesbury. There, I made my first contact with psychiatry, with Skottowe who was just introducing ECT at St John's Hospital. Then we came back to London but were again evacuated, this time to Wolverhampton; but for some reason I went via Cambridge, where I got a job as a houseman because they were so short of junior doctors at Addenbrooke's. So I studied for my surgery and got paid for it at the same time, while living in a fantastic house-the Granary on Silver Street Bridge, part of Darwin's home. It belonged to the Director of Education, who revived my interest in architecture. He had people like Gropius come to stay and the young modern architects of the time, who were designing his 'village colleges' and schools. These were pioneering endeavours, which provided the pattern for many of the post-war schools. So that was a happy year, but it did not go down well with the Middlesex Hospital, as I should really have been at Wolverhampton. But still, I and a friend from Stowe struggled through our exams and passed them. As a student, I was interested in psychosomatics and found it natural to see stress as a factor in illness. I remember being shocked when a senior cardiologist went into paroxysm of rage with a patient who complained of tachycardia and extrasystoles of a nervous kind. He seemed to feel that this unhappy man was there just to tease and provoke him!

HF You qualified in medicine then and started out on your first medical job. What were your experiences then?

PS My emotional ties were with Cambridge (where I married a German refugee), so I applied for a job as a house physician in Bury St Edmunds, at the Royal West Suffolk Hospital. But one knew then one was just marking time until joining the RAMC. There, I met up again with many old friends from Cambridge and the Middlesex. I particularly remember my entrance into Crookham, saluting smartly at the gate, and knocking my cap off. I was that sort of a soldier! Eventually, I was sent on a tropical medicine course and boarded a ship to India, which I was really looking forward to. I had lots of books on the subject. However, we stopped off at Freetown for training in Grafton Valley, which the Malaria Unit told me had the highest infection rate for mosquitoes in the world; this was where the Army sited the hospital! Consequently, I got malaria there and was in a sort of semi-coma when the Unit moved on to India and Burma, and this I always regretted. However, I did then have a fascinating job in Sierra Leone. They made me Recruiting Medical Officer for the colony. We went up country on a tiny railway and then walked through the bush for a couple of weeks, going from village to village picking up recruits for the army. I think each headman was told to produce so many volunteers. This was pristine, untouched tribal life such as it would now be difficult to find anywhere. It was a really unique experience and my sorrow is that I did not have an anthropological training to take more advantage of it. There were Leopard and Baboon societies, through which a chief of a village imposed his influence and exercised power; tribal dancing and drumming, and primitive rites for pubertal men and women were still practised as was voodoo: natives who violated tribal laws died and we found nothing at PM.

HF So after leaving Africa, you had a short spell in Germany at the end of the war and then I think you came to your demob.

PS When I was demobbed, I still had this crazy idea about wanting to study the pathophysiology of emotions, so I decided to try and get my Membership and then go to a mental hospital and get a grounding in psychiatry. My rather vague notion was that I would become a physician who specialised in those disorders in which there is a large emotional component, rather than becoming a psychiatrist, of which I think I was a little bit nervous. In the event, there were more of us demobbed than there were jobs and I became tired of going on refresher courses. I decided instead to reverse the order and do my stint in the mental hospital first and then go and improve my general medicine afterwards. So I went to Bexley Hospital, which was then go-ahead with Leslie Cook in charge; he was a nice man to learn from and work with. While I was there, I took my DPM.

HF What were your impressions of your first experience of a mental hospital?

PS I was really rather alarmed and horrified when I first went in. It was so unlike the tidy, orderly, clean 
atmosphere of a general hospital. Another early impression was how skilled and devoted to their patients the male nurses were at that time. A lot of them were men who had come down from the north during the depression. The male wards needed so little paraldehyde compared with the female ones, and I found this remarkable. Very quickly, I got extremely interested in the work and attached to the patients. Also, of course, we were very spoilt then. We had a farm, and wonderful food, much better than they were having at the Ritz: strawberries and cream and marvellous great joints used to come up to the wards-for the patients as well. Another aspect of the place was the sense of community in the hospital; nurses and doctors were still rather alienated people, so we tended to cling together!

Another of my early impressions was that some of the patients were much more treatable than at first appeared and how a success could bolster one's confidence. I recall, for example, a lady who had been in the hospital for some years. I established that she was suffering from bromide poisoning. On stopping her bromides another condition emerged; she was suffering from an agitated depression and when we gave her ECT, she got better and went out. This made me feel that there was a lot more one could do than I had first imagined.

HF What was the next stop after Bexley?

PS Well, I got my DPM and apparently, but I did not know this, there was a job advertised for a registrar, or the equivalent to it, at the observation ward at St Francis in Dulwich. Dr Cook was away and Dr Comerford, his deputy, was in charge; a warm, kind, and rather eccentric man. He wrote to St Francis' in my name, applying for the job. He thought I ought to get a move on! I certainly was rather stuck at Bexley in a way; my wife was very ill in a sanatorium nearby and it never occurred to me to leave and apply for the job. But he had me up and said, "You've got a job at St Francis observation ward", and-this is rather typical of me-I said "Well, this is the way it is," so off I went. Dr Comerford was quite right. The observation ward provided a wonderful experience in acute psychiatry and I enjoyed it, especially Professor Lewis' fortnightly visits to advise us on the more difficult cases and what their disposition should be. I got on very well with him. I used to tease him about coming down on the tram and wondered why he made the social workers cry when he quizzed them about the patients. He liked this and it was only later on that he made me nervous too! One day, I told him I was perplexed by the suicide attempters and indeed why people killed themselves. This set him off saying "Oh Sainsbury, haven't you read Faris and Dunham?", "No sir", "Do you know Durkheim's work on suicide?", "No", "Do you know Booth's survey of London?", "No", "Oh well, you might find something interest- ing there". It took me a year to see what he was getting at, to read these books, and to gather that he was suggesting that I did some kind of social epidemiological survey of suicide.

HF Was this how you got interested in suicide in the first place?

PS Yes, I often think of this encounter with Aubrey and wonder why was I interested in suicide. Prior to joining the observation ward, I had never had to talk and cope with people who had seriously wanted to kill themselves. I think I was genuinely concerned and amazed; it seemed so unbiological and somehow tragic.

HF What was your next move then, from St Francis?

PS Well again, it was not taken by me; it was taken by Aubrey Lewis, who asked wouldn't I like to come up to the Maudsley and, he hinted, do research? But he added that $I$ needed to fill in the gaps in my psychiatric experience, and proposed I go to child psychiatry first. So I did six months with Kenneth Cameron and that was a very interesting period. Then it really baffled me when Professor Lewis said he wanted me to go full time into research, and suggested that I devoted myself to this study of the ecology of suicide for my MD and a Maudsley monograph. Within a month of starting it I realised I was on a good wicket, that there was not only an immense reservoir of statistics on suicide but also of social data on the London boroughs, and that they could be related to one another in all kinds of ways. It quickly became evident that this was very economical research. Here was a wealth of data which could easily be exploited and so I was soon able to tell Professor Lewis that I was making good progress, and this seemed to please him. He then arranged what, I suppose, was the next step in my career. He appointed Sydney Crown and me to be full-time research workers at the Maudsley, with rooms in the basement of a house on Denmark Hill. His suggestion was that tics and other spontaneous movements merited study, and with this end in view, he had already begun negotiations with an electronic expert at St Thomas's, Peter Styles, who had developed a device able to record and count the activity in muscles-something that was quite novel at the time. So he presented me with this wonderful apparatus and told me to get on with it, which I did with relish, using this apparatus and frame analysis of cinéphotography to count tics and relate their occurrence to a variety of circumstances.

I became particularly interested in 'muscle tension' and the kind of symptoms psychiatric patients complain of: backache, writer's cramp, headaches, and so on. So together with John Gibson, I began some studies on anxiety and these muscular symptoms. My next step was to use the same device to measure gestural activity in psychiatric patients. To do this, we gave the patients interviews in which we first 
discussed bland topics and then stepped on their psychiatric corns, while counting the changes in gestural activity which occurred when the emotionally disturbing topics were introduced. Gesture was an aspect of behaviour in which I remained interested for the rest of my working life.

HF So, there came a point then when you had to decide whether you were going to devote yourself to a life of research or go into more direct clinical work.

PS Yes, I rather panicked at this point and as there was a clinical job going at the Westminster Hospital, I applied for that. I felt anxious about devoting myself solely to research, I was not confident of my ability for it, and I was very contented doing clinical work. So I started with Garmany at the Westminster. Well, during this time I had to give a lecture about my work at the Maudsley on movement and muscle tension, and Aubrey Lewis was in the Chair. While I was giving the lecture and in the gap between slides, Aubrey said "would you like to join the MRC?" I was never a good lecturer and this made me even more incoherent than usual. So a few days later, I formally applied for the post of Director of the Research Unit at Graylingwell.

HF Was that the job which had been vacated by Martin Roth?

PS Yes. The reason it was vacant was because Martin had just been appointed to the Chair at Newcastle; but his outstanding work at Graylingwell had prompted the MRC to take over the clinical research there, though this had not yet been implemented. In 1956 , the MRC was assessing research being conducted in all NHS hospitals with a view to supporting those departments they approved of. As Martin was no longer available, they needed to grab someone. My interview at the MRC was amusing and quite typical of Professor Lewis. While I waited my turn, other applicants came away from their encounter with remarks such as "My God, it's rough in there", so I entered with some trepidation, but it so happened that as each question was put to me, Aubrey Lewis was ready with my answer! There was going to be no doubt about who was to have the job, and he was not going to let me mumble and fumble and put them off.

HF How did you feel about your life being sort of directed in this way?

PS It's most satisfying-making choices is very unsettling. But seriously, that is a question I often ask myself. Perhaps I'm a bit of a fatalist. In this instance, however, this opportunity was so manifestly attractive that I would have been a fool and a coward not to have had a go at it. As on other occasions, some generous patron had formed a more optimistic opinion of me than I had. Looking back on my life, I can see that fortune and kindly people have indulged me. Aubrey happened to like me, he was my sponsor, and urged me along in a way I could not have done by myself. Given my sort of diffidence, I can only feel grateful to those who took on the task.

HF So at that point, you left London and moved to Chichester.

PS Yes, and then there was the problem of what the research programme of the Unit was going to be. I have always preferred dry facts to juicy theories, and clinical research tends to the applied kind anyway. Through my own inclinations and the staff that were available, there was a premium on work on the psychophysiology of symptoms, and on the epidemiology and statistics of suicide and other disorders. The Unit's early endeavours involved a study on personality and psychosomatic disorders in all patients attending the general hospitals in Chichester and a survey of mental illness in a New Town, Crawley, which was in our catchment area. Indeed, my choice of projects was often determined by the particular opportunities our district presented to us. In West Sussex, for instance, we had a quite unique opening for research into the psychiatric services, and this was something that tallied nicely with my interests. Dr Carse, the Superintendent of the hospital, had, in 1957, just introduced the Worthing experiment - a real innovation in community care. This was a psychiatric service in which every patient referred was first seen in the community, either at home or at a day hospital. Moreover, the patients were then treated as far as possible in one of these settings, rather than by admission to Graylingwell. It was a 24-hour service, efficiently organised and operated in close conjunction with the GPs. But it also provided the research unit with a novel opportunity. So we started an evaluative study, comparing this community service with a hospital-based service in Salisbury, a district which is demographically similar to the Chichester one. A lot of our findings and comments on community care nearly 30 years ago now have an all too familiar ring about them; that it can only succeed clinically and avoid burden and distress in the family if the service ensures that adequate social and psychiatric support is provided in the community. Without that, everyone is in dire trouble, but given the facilities and skilled personnel, community care does work because, on the whole, patients' families and GPs prefer this alternative.

HF Do you happen to know how it was that Carse got on this track in the first place?

PS I do not know how he got in touch with Querido, who had set up a service of this kind in Amsterdam. But Carse went over to Holland, saw what they were doing there, got sold on their ideas, came back, and introduced and adapted them to meet the needs and circumstances of West Sussex.

HF One criticism made at the time of the Worthing experiment was that it was done rather in isolation from the local authority community services. 
PS This was absolutely the case. It was remarkable to see how the social workers in the hospital reacted too. They were so used to taking clinical histories for the psychiatrists that they were quite at a loss as to their new role. They could not get away from the habitual way of working. But oddly enough, the social workers in the hospital-based service in Salisbury clearly recognised their function as one of supporting the patient's family and coming to grips with the problems of out-patients.

HF You did find, though, that a greater degree of hospital care reduced the burdens on the families, at least for some categories of patients.

PS Yes. The burdens were relieved on families when the patient was admitted. Nevertheless, families in the community service were very tolerant of the extra burden which they had. Although the burden on the family was increased for those in the community yet support was given to the family, but in Chichester it was usually given by the psychiatrists. They visited the patient at his home and collaborated with the GP. Where this kind of support was provided, the burden was reduced as much in the community service as in the hospital one, and it was found to be more acceptable to the family. The family were prepared to take on a lot of extra commitments, providing they were assured of some regular backing, whether by the day hospital, the pychiatrist, the GP, or the social worker.

HF Was it true to say, as I think some people said at the time, that Graylingwell at the beginning of the experiment had an unusually high admission rate, compared with the rest of country?

PS I am not too sure of that. All I can say is that in our controlled comparison of the two, $80 \%$ of the referrals to the psychiatrists in Salisbury were admitted, whereas only $14 \%$ were admitted in Chichester. So even if Chichester had a high admission rate, this would not explain this enormous decrease.

HF Are there any other implications of this comparative work of yours for the situation that we are in today with the mental health services?

PS Well, I think that a lot of what we said at that time about the problems that are entailed in establishing an effective community psychiatric service are now recognised as evident. You cannot do community care on the cheap. The Department of Health was very interested in our study to begin with, because I believe they saw it as an economical way of providing care. Our original intention was to include a costeffectiveness study in our evaluation, but we were unable to recruit an economist. Community care is costly on personnel. Indeed, it's almost irresponsible to introduce such a service unless this fact is honestly faced, as well as recognising the importance of ensuring an effective organisation not only for maintaining contact with patients being treated extramurally but also for providing skilled support.
Another aspect of the study, though of a different kind, that made a great impression on me is the enthusiasm with which all levels of staff in a mental hospital welcome, assist, and do their best to promote a research project. Providing its purpose and their contribution is made clear to them, they enjoy collaborating and sharing in the endeavour. This was true of the GPs too. So one ends up with a really fine research team of nurses, doctors, social workers, etc.

HF What about the practical difficulties of carrying out a large research programme and getting all the data to a published form?

PS Actually, we had two problems. We did not publish nearly as much of this study as we ought to have done, partly because we were always in a hurry to get on with the next thing but also because this was the first large-scale survey of any kind to go on a computer. The Atlas in Manchester was the most advanced computer in the world then and a programme was developed to analyse our data, but the whole thing just would not quite work, so we have never fully exploited it. Nor did I really get down to the huge task of taking it all off Atlas and reprogramming the data for a later generation of computer. This has always been a terrible regret of mine. I should have put other things on one side and got a new member of staff to recode and make the data available in another form.

HF Could you talk about some of the other things that you were interested in at your unit?

PS One of the projects that I and other members of the Unit got very interested in were case registers. Here was an immense pool of information waiting to be exploited, and we tried to use it in various ways. John Birtchnell did some valuable epidemiological studies using the North-East Scotland case register, and Jackie de Alarcon set up one in Southampton which was specifically tailored to evaluating services. This case register accumulated details of the type of care patients received over the years, as well as recording social and clinical items. Unhappily, funds were withdrawn when the NHS policies were revised, and the plan agreed with the Region to evaluate the mental health services in Southampton by comparing the half of the city based on a District General Hospital with the other half based on Knowle Mental Hospital had to be abandoned. What an absurd waste of money, opportunity, and work: administrators and doctors are still asking the questions we hoped to try to answer 15 years ago. Now even the register is closed. It makes my back ache!

However, Birtchnell's epidemiological studies on birth order and early bereavement in relation to psychiatric disorder are nice examples of the uses to which registers can be put. Richard d'Alarcon set up a register and undertook an interesting and 
pioneering survey of drug dependence in our district, but very sadly Richard became ill, and much of his work was never published.

I found uncompleted work to be a major difficulty in directing a research unit. A psychiatric project often takes two or three years to plan, implement, analyse, and then write up. The real problem arises at this last stage of publishing. What happens is that as the researcher's appointment comes to an end, he applies for and obtains a consultant post. He really believes he will finish writing up the work after leaving, but in fact never finds the time. This happened to three or four good projects. I should have been tougher and made sure the work was finished.

Other projects which especially interested me and which we did publish were Kreitman and Nelson's work on mental disorder in married couples, a study on the psychophysiology of hypertension, and an ultrasonic device to measure gestural and psychomotor behaviour, developed with Mr Haines. (As a psychiatrist, I was always very proud that this apparatus was exhibited at the physicists' annual exhibition at Alexandra Palace). Dr Shaw was with the Unit from day one, and made some very original contributions to methods of analysing the EEG which had important clinical implications for dyslexics and schizophrenics. I must mention $\mathrm{Dr}$ Levey's interesting studies on classical conditioning and $\mathrm{Dr}$ Knowles' on the placebo response, while $\mathrm{Mr}$ Jenkins and I enjoyed working on a commission from WHO to investigate the social and other factors affecting suicide trends in Europe and in particular its decline in England. But the best of the work on suicide and that which brought me most pleasure was that of Brian Barraclough. I had not intended to reply to your question at such length!

HF Have you any ideas on how research could be better organised in the future, so that it would be more productive and make better use of its resources? miserly and illiberal age. The MRC of course, really had the right idea and one which used to make it the envy of research workers the world over; namely, its policy of giving a good proportion of its scientific staff tenured appointments. This not only attracted people to a career in research, but enabled them to undertake more ambitious, long-term investigations. But such support is currently not very popular, so short-term grants, which often allow one to touch the edges of a problem, now tend to prevail and they are not now as amply provided as they should be in this country with its research ethos (which will wither if it's not nourished). I think we need to ensure more opportunities both for young psychiatrists to be exposed to research and for more formal training in research design and methods. We might provide some regional organisation whereby

panels of experienced research workers would be available to advise, assist, and direct psychiatrists who are seriously intent on investigating a problem. I tried to promote a scheme of this kind when I was Chairman of the RMPA's research committee, but it never really caught on. I very much like the idea of the College setting up a research department. It could provide some of the facilities I have just mentioned.

Attracting funds for psychiatric research is another matter. In the RMPA committee, I made quite good progress in liaising with the pharmaceutical industry's institute on research. They were keen to collaborate, but for some reason which I never understood, the rest of the committee did not like it. I think it might be worth trying again.

As an aside, I would like to mention that I strongly favour placing research departments in the mental hospital (and its district services), rather than confining them to the universities. The day-to-day problems of clinical psychiatry and of providing psychiatric services are most conspicuous there, and opportunities for getting pertinent ideas present themselves daily.

HF Since your retirement from the Unit, have you continued to work on your research data to publish new findings?

PS I have done a bit of publishing, but I think I had intended to do more than I have done. I mentioned that we did a quite interesting study on Suicide Trends in Europe for WHO. One of the things I had resolved to do was to write this up for publication, and this is still on my list of tasks; otherwise, I have written some papers for conferences, chapters in books, but very little new work.

HF Could we talk about your College activities?

PS The College (and RMPA) and my various assignments with the two institutes have been of the utmost importance to me in both my professional and personal life. I think I have been, at one time or another, a member of every committee they have managed to devise, despite my ineptitude in that role.

When I became Director of the MRC Unit at Graylingwell, I instantly inherited Professor Roth's position as Chairman of the RMPA's Research Committee. This, and other commitments to the College, kept me in touch with other psychiatrists and many friends, and this was a continuous source of pleasure. The College was a kind of club that spared me becoming a recluse in the Sussex steppes.

I cannot remember how I became a Vice-President, when Linford Rees was the President, though I know I felt very proud to be one. In that office, it fell to me to interview Plyusch, the first Russian 'psychiatric' dissident to come to the College. This was one of the events which led Council to set up a Special Committee on the Political Abuse of Psychiatry, of 
which I became Chairman. Its deliberations were always engrossing, often led to interesting decisions, sometimes to real successes in helping dissidents or in influencing attitudes, and once, with Sidney Levine, to a remarkable encounter at the Soviet Embassy.

HF Have you any summarising thoughts on your career in psychiatric research, particularly which might be of interest to those who are starting out today on a similar road?

PS I do feel if one is sufficiently motivated and there is a problem which you really know you want to pursue, this is probably the essential preliminary to research. It is amazing the extent to which things become possible when you know what you want to investigate.

I know I have had a lot of luck. Nevertheless, I do believe that if there is an idea, an area of inquiry which truly enthrals and preoccupies you, then the motivation to read about it, worry about it, and then to formulate a viable research project will follow. The funds, or even recruitment to a research team, despite the current squalid neglect of support for psychiatric research, will also materialise. 